\title{
Study on the Relationship between Metacognitive Strategies and English Reading Anxiety for Fashion Majors
}

\author{
Chunyan LIAO \\ School of Foreign Languages, Wuhan Textile University Wuhan, 430073, China \\ email: cinderellaandfish@126.com
}

Key words: Metacognitive strategies; Fashion majors; English Reading Anxiety; English Reading Scores

\begin{abstract}
This study is based on the theory of metacognitive strategies and English reading anxiety. In order to get the values of students' English reading anxiety and metacognitive strategies, we use Saito's Foreign Language Reading Anxiety Scale and Yin Xiaojuan's modified version as the tools, and the English reading comprehension test in the experiment. This research examines the situations of the Fashion majors' English reading anxiety and metacognitive strategies in Chinese university and the correlation between the FLRAS and MSQ.
\end{abstract}

\section{Introduction}

Studies of English learning strategies in China began in the early 1990s; Psychologist Lin Chongde and Xin Tao (1996), Chen Yinghe (1996) did a lot of researches in their writings on metacognitive structure. [1] Chinese scholars Cao Feng and Zhu Manshu (1989) studied the children's development of reading comprehension monitoring capabilities. [2] Li Weijian (2004) did the reading comprehension monitoring experiment on the students who had reading difficulties. Xiao Wuyun (2011) did an empirical research in a university, usingmetacognitive strategies training to improve students' English learning autonomy and English achievements. [3] This study explores the correlation of Fashion majors' English reading anxiety and metacognitive strategies, involving the influence on the English reading comprehension scores.

\section{Research Methodology}

\section{A. Research Questions}

a. What is the current situation of the Fashion majors' usage of metacognitive strategies in reading?

b. Are there any correlations between metacognitive strategies and English reading anxiety?

\section{B. Subjects}

83 Fashion sophomores of Grade 2014 from two different English classes in Wuhan Textile University are invited in this research. Class One, as the experimental group (EG), has 41 students (49.3\%); Class Two, as the controlled group (CG), has 42 students (50.7\%). Their majors include physics, computer, sociology, political education, and so on.

\section{Instruments}

The two questionnaires are Foreign Language Reading Anxiety Scale (FLRAS) and Metacognitive Strategies Questionnaire (MSQ). FLRAS can measure the level of foreign language reading anxiety which is designed by Saito et al. MSQ had been used to study the University Students' Metacognitive Strategies. [4] [5] It can fully explore all the aspects of the metacognitive strategies employed in this study. 


\section{Result and discussion}

Table 1 Correlation between MSQ and FLRAS

\begin{tabular}{|l|l|l|}
\hline Variables & \multicolumn{2}{|l|}{ MS } \\
\hline \multirow{4}{*}{ ERA } & Pearson Correlation & $-.341^{* *}$ \\
\cline { 2 - 3 } & Sig. (2-tailed) & .002 \\
\cline { 2 - 3 } & $\mathrm{N}$ & 83 \\
\hline \multirow{2}{*}{$* *$ Correlation is significant at the 0.01 level. }
\end{tabular}

From the perspective of the related analysis results of Table 1, Pearson correlation coefficient $r=$ -.341, $\mathrm{P}<.01$. It shows that there are negative correlation between MSQ and FLRAS. That means the less the students use MS, the higher degree of ERA they have. The use of MS in English reading will affect the students' ERA levels, and it can also be used as a way to reduce the ERA.

\section{A. The Independent Samples Test of pre-test}

Table 2 Group Statistics of Pre-test MSQ

\begin{tabular}{|l|c|c|c|c|c|}
\hline & Groups & $\mathrm{N}$ & Mean & Std. Deviation & Std. Error Mean \\
\hline The Pre-test of & EG & 42 & 79.88 & 12.981 & 2.003 \\
MSQ & CG & 41 & 78.07 & 13.803 & 2.156 \\
\hline
\end{tabular}

From Table 2 we can see the Group Statistics of Pre-test MSQ. The number of EG is 42 and of CG is 41. The means are 79.88 and 78.07. For Std. Deviation, EG is 12.981, CG is 13.803; Std. Error Means are 2.003 for EG and 2.156 for CG.

Table 3Independent Samples Test of pre-test MSQ

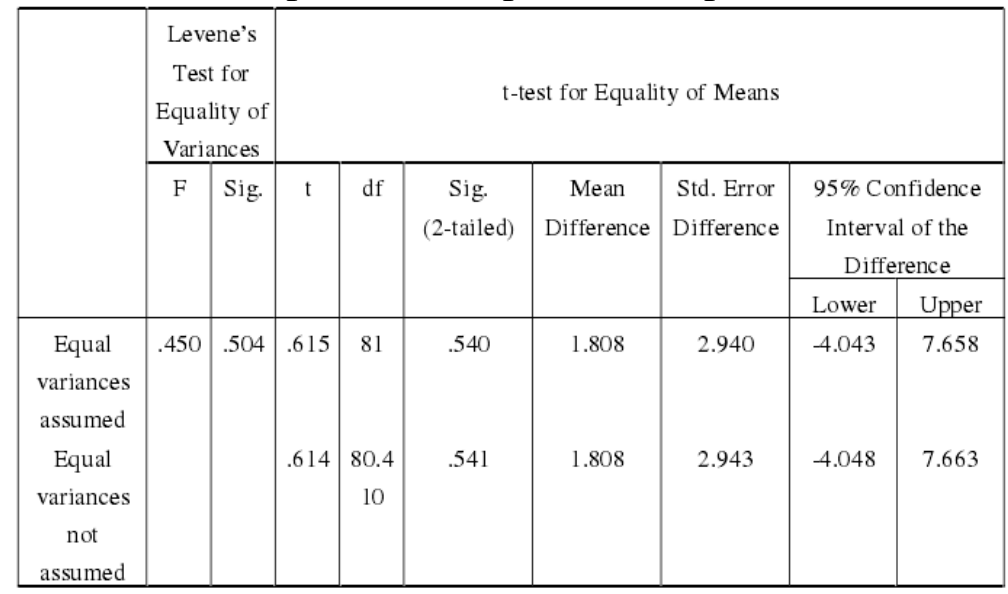

The Independent Samples Test shows that there is no significant difference between the EG and CG in MSQ ( $\mathrm{t}=.615, \mathrm{df}=81, \mathrm{p}>.05)$, and their Mean Difference is 1.808 . Since $95 \%$ Confidence Interval of the Difference includes 0, and p value is bigger than .05.

B. The Independent Samples Test of post-test

Table 4 Group Statistics of Post-test MSQ

\begin{tabular}{|c|c|c|c|c|c|}
\hline & Groups & $\mathrm{N}$ & Mean & Std. Deviation & Std. Error Mean \\
\hline Post-test of & EG & 42 & 83.86 & 11.742 & 1.812 \\
\hline MSQ & $\mathrm{CG}$ & 41 & 78.46 & 12.118 & 1.893 \\
\hline
\end{tabular}

From Table 4 we can see the Group Statistics of Post-test MSQ. The number of EG is 42 and of CG is 41 . The means are 83.86 and 78.46. The value in EG is bigger than the pre-test 3.78, and the value in CG is smaller than the pre-test 0.39. For Std. Deviation, EG is 11.742, CG is 12.118; Std. Error Means are 1.812 for EG and 1.893 for CG. 
Table 5 Independent Samples Test of post-test MSQ

\begin{tabular}{|c|c|c|c|c|c|c|c|c|c|}
\hline & $\begin{array}{r}\text { Levene } \\
\text { for Equ } \\
\text { Varia } \\
\end{array}$ & $\begin{array}{l}\text { Test } \\
\text { lity of } \\
\text { ces } \\
\end{array}$ & & & t-test & for Equality & of Means & & \\
\hline & F & Sig. & $t$ & df & $\begin{array}{c}\text { Sig. } \\
\text { (2-tailed) }\end{array}$ & $\begin{array}{c}\text { Mean } \\
\text { Difference }\end{array}$ & $\begin{array}{l}\text { Std. Error } \\
\text { Difference }\end{array}$ & $\begin{array}{r}95 \% \mathrm{Co} \\
\text { Interva } \\
\text { Diffe }\end{array}$ & $\begin{array}{l}\text { fidence } \\
\text { of the } \\
\text { ence }\end{array}$ \\
\hline & & & & & & & & Lower & Upper \\
\hline $\begin{array}{l}\text { Equal } \\
\text { variances } \\
\text { assumed }\end{array}$ & .356 & .553 & 2.059 & 81 & .043 & 5.394 & 2.619 & .183 & 10.605 \\
\hline $\begin{array}{l}\text { Equal } \\
\text { variances } \\
\text { not } \\
\text { assumed }\end{array}$ & & & 2.059 & 80.748 & .043 & 5.394 & 2.620 & .180 & 10.607 \\
\hline
\end{tabular}

The Independent Samples Test shows that there is significant difference between the EG and CG in MSQ ( $t=2.059, \mathrm{df}=81, \mathrm{p}<.05)$, and their Mean Difference is 5.394. Since 95\% Confidence Interval of the Difference does not include 0, and p value is smaller than .05.

Table 6 Group Statistics of Post-test FLRAS

\begin{tabular}{|l|l|c|c|c|c|}
\hline & Groups & N & Mean & Std. Deviation & Std. Error Mean \\
\hline Post & EG & 42 & 58.74 & 8.546 & 1.319 \\
FLRAS & CG & 41 & 62.59 & 8.709 & 1.360 \\
\hline
\end{tabular}

From Table 6 we can see the Group Statistics of Post-test FLRAS. The number of EG is 42 and of CG is 41. The means are 58.74 and 62.59. The value in EG is lower than the pre-test 9.31, and the value in CG is lower than the pre-test 2.07. For Std. Deviation, EG is 8.546, CG is 8.709; Std. Error Means are 1.319 for EG and 1.360 for CG.

Table 7 Independent Samples Test of post-test FLRAS

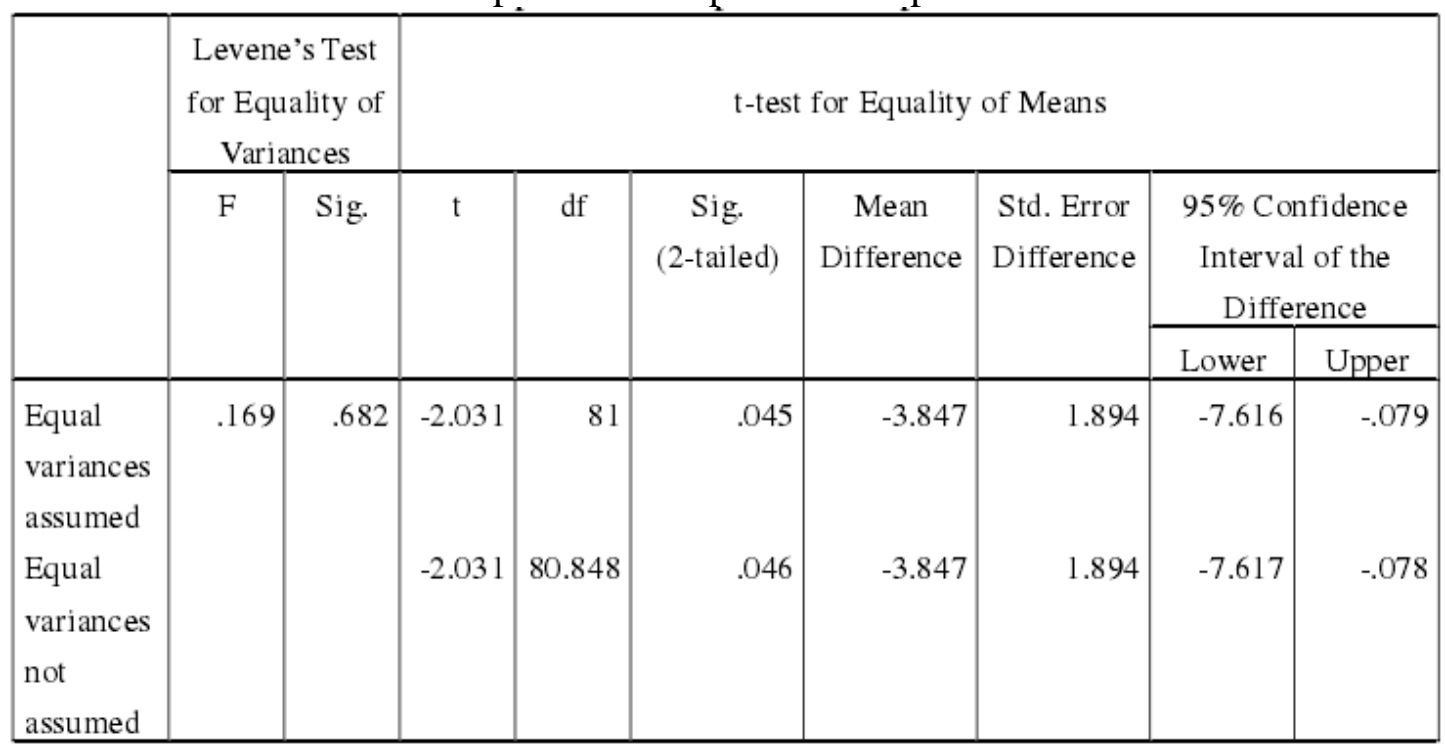

The Independent Samples Test shows that there is significant difference between the EG and CG in FLRAS $(\mathrm{t}=-2.031, \mathrm{df}=81, \mathrm{p}<.05)$, and their Mean Difference is -3.847 . Since 95\% Confidence Interval of the Difference does not include 0, and p value is smaller than 0.05 . The Independent Samples Test of post-test shows there is significant difference between EG and CG in both MSQ and FLRAS, the metacognitive strategies training is useful for improving the learners' metacognitive strategies using level and reducing their reading anxiety. So as to ensure the conclusion, paired samples test is used. 


\section{Paired Samples Test of MSQ}

Table 8 Paired Samples Statistics of MSQ

\begin{tabular}{|l|l|r|r|r|r|}
\hline \multicolumn{2}{|c|}{} & \multicolumn{1}{c|}{ Mean } & N & Std. Deviation & Std. Error Mcan \\
\hline Pair 1 & Pre MSQ of CG & 78.07 & 41 & 13.803 & 2.156 \\
& Post MSQ of CG & 78.46 & 41 & 12.118 & 1.893 \\
\hline Pair 2 & Pre MSQ of EG & 79.88 & 42 & 12.981 & 2.003 \\
& Post MSQ of EG & 83.86 & 42 & 11.742 & 1.812 \\
\hline
\end{tabular}

Table 8 is the Paired Samples Statistics of MSQ, from this table, we can see that the mean of pre-test CG is 78.07, EG is 79.88, of post-test CG is 78.46, EG is 83.86. The Std. Deviation in Pre MSQ of CG is 13.803, in Post MSQ of CG is 12.118, in Pre MSQ of EG is 12.981, in Post MSQ of EG is 11.742 .

Table 9 Paired Samples Test of MSQ

\begin{tabular}{|c|c|c|c|c|c|c|c|c|c|}
\hline & \multicolumn{5}{|c|}{ Paired Differences } & \multirow[b]{3}{*}{ t } & \multirow[b]{3}{*}{$\mathrm{df}$} & \multirow{3}{*}{$\begin{array}{c}\text { Sig. } \\
\text { (2-tailed) }\end{array}$} \\
\hline & & \multirow[b]{2}{*}{ Mean } & \multirow{2}{*}{$\begin{array}{c}\text { Std. } \\
\text { Deviation }\end{array}$} & \multirow{2}{*}{$\begin{array}{c}\begin{array}{c}\text { Std. Error } \\
\text { Mean }\end{array} \\
\end{array}$} & \multicolumn{2}{|c|}{$\begin{array}{c}95 \% \\
\text { Confidence } \\
\text { Interval of the } \\
\text { Difference }\end{array}$} & & & \\
\hline & & & & & Lower & Upper & & & \\
\hline Pair 1 & $\begin{array}{l}\text { Pre MSQ of CG- } \\
\text { Post MSQ of CG }\end{array}$ & -.390 & 3.714 & .580 & -1.563 & .782 & -.673 & 40 & .505 \\
\hline Pair 2 & $\begin{array}{l}\text { Pre MSQ of EG- } \\
\text { Post MSQ of EG }\end{array}$ & -3.976 & 2.745 & .424 & -4.832 & -3.121 & -9.387 & 41 & .000 \\
\hline
\end{tabular}

The results are displayed in Table 9: the results of Paired Samples Test of MSQ shows that there is not significant difference between the Pre MSQ of CG and Post MSQ of CG $(\mathrm{t}=-.673, \mathrm{df}=40, \mathrm{p}>.05)$, the 95\% Confidence Interval of the Difference includes 0, there is not statistic meaning. It means that there are no significant changes in metacognitive strategies aspect for the CG students. To of EG $(\mathrm{t}=-9.387, \mathrm{df}=41, \mathrm{p}<.05)$, the $95 \%$ Confidence Interval of the Difference

does not include 0 , there is statistic meaning. It means that the training on metacognitive strategies is effective.

\section{Paired Samples Test of FLRAS}

Table 10 Paired Samples Statistics of FLRAS

\begin{tabular}{|l|l|c|c|c|c|}
\hline \multicolumn{2}{|c|}{} & Mean & $\mathrm{N}$ & Std. Deviation & Std. Error Mean \\
\hline Pair 1 & Pre FLRAS of CG & 64.66 & 41 & 10.403 & 1.625 \\
& Post FLRAS of CG & 62.59 & 41 & 8.709 & 1.360 \\
\hline Pair 2 & Pre FLRAS of EG & 68.05 & 42 & 9.662 & 1.491 \\
& Post FLRAS of EG & 58.74 & 42 & 8.546 & 1.319 \\
\hline
\end{tabular}

Table 10 is the Paired Samples Statistics of FLRAS, from this table, we can see that the mean of pre-test CG is 64.66, EG is 68.05, of post-test CG is 62.59, EG is 58.74. The Std. Deviation in Pre FLRAS of CG is 10.403, in Post FLRAS of CG is 8.709, in Pre FLRAS of EG is 9.662, in Post FLRAS of EG is 8.546. The Std. Error Means of Pre FLRAS of CG and EG, Post FLRAS of CG and EG are 1.625, 1.491, 1.360 and 1.319. The mean of CG is decreasing, the same with EG. That is to say the significant difference between the two groups in the post-test FLRAS is not because of the CG's increase, but based on the changing degrees of the two groups.

Table 11 Paired Samples Test of FLRAS

\begin{tabular}{|c|c|c|c|c|c|c|c|c|c|}
\hline & \multicolumn{5}{|c|}{ Paired Differences } & \multirow[b]{3}{*}{ t } & \multirow[b]{3}{*}{$\mathrm{df}$} & \multirow{3}{*}{$\begin{array}{c}\text { Sig. } \\
\text { (2-tailed) }\end{array}$} \\
\hline & & \multirow[b]{2}{*}{ Mean } & \multirow{2}{*}{$\begin{array}{c}\text { Std. } \\
\text { Deviation }\end{array}$} & \multirow{2}{*}{$\begin{array}{c}\text { Std. Error } \\
\text { Mean }\end{array}$} & \multicolumn{2}{|c|}{$\begin{array}{l}95 \% \text { Confidence } \\
\text { Interval of the } \\
\text { Difference }\end{array}$} & & & \\
\hline & & & & & Lower & Upper & & & \\
\hline Pair 1 & $\begin{array}{l}\text { Pre FLRAS of CG- } \\
\text { Post FLRAS of CG }\end{array}$ & 2.073 & 9.456 & 1.477 & -.912 & 5.058 & 1.404 & 40 & .168 \\
\hline Pair 2 & $\begin{array}{l}\text { Pre FLRAS of EG- } \\
\text { Post FLRAS of EG }\end{array}$ & 9.310 & 3.803 & .587 & 8.124 & 10.495 & 15.864 & 41 & .000 \\
\hline
\end{tabular}


In terms of FLRAS, Paired-Samples Test is used to test the changes of FLRAS in the pre-test and post-test. The results are displayed in Table 4.20: the results of Paired Samples Test of FLRAS shows that there is not significant difference between the Pre FLRAS of CG and Post FLRAS of CG ( $\mathrm{t}=1.404, \mathrm{df}=40, \mathrm{p}>.05)$,the 95\% Confidence Interval of the Difference includes 0, there is not statistic meaning. It means that there are no significant changes in reading anxiety aspect for the CG students. To the EG, there is significant difference between the Pre FLRAS of EG and Post FLRAS of EG ( $\mathrm{t}=15.864, \mathrm{df}=41, \mathrm{p}<.05$ ) , the 95\% Confidence Interval of the Difference does not include 0 , there is statistic meaning. It means that the training on metacognitive strategies make effects on their reading anxiety.

\section{Conclusion}

Through the analysis of the data, nearly $10 \%$ of the students are in the high anxiety group (9.64\%). From the testing results of correlation coefficient, it shows that there are negative correlation between MSQ and FLRAS. That means the less the students use metacognitive strategies, the higher degree of English reading anxiety they have. The usage of metacognitive strategies in English reading affects the students' English reading anxiety, and it can also be used as a way to reduce the reading anxiety. This research and results add to the knowledge tree of metacognitive strategies and English reading anxiety, and expand our version of their relationship. The analysis of the strategies' structure can determine its psychological component, connection and the order. So the teaching steps can become concrete, operational, and convenient to teaching.

\section{References}

[1] Flavell, J. H. (1981). Cognitive monitoring. In Dickson, W P (Ed.), Children's .Oral Communication Skill (pp.134-136). New York: Academic press.

[2] Clement, R. \& Smythe, P. C. (1977). Motivational variables in second language acquisition. Canadian Journal of Behavior Science, 6(9), 84-90.

[3] Chamot, A. U. \& O’Malley, J. M. (1994). The CALL Handbook: Implementing the Cognitive Academic Language Strategy Learning Approach Reading. MA :Addison-Wesley.

[4] Bachman, L. (1990). Fundamental Considerations in Language Testing. Oxford: Oxford University Press.

[5] Suzanne Hidi. Interest: A unique motivational variable [J]. Educational Research Review.2006 (2) 